\title{
MÉTOdO PARA DETERMINAÇÃo DE RESídUOS DE CLORPIRIFÓS EM ALFACE POR CROMATOGRAFIA A LÍQUIDO DE ALTA EFICIÊNCIA*
}

\author{
MARILENA FERREIRA PENA" \\ ELIANE HOOPER AMARAL \\ EDUARDO VON SPERLING \\ IVAN CRUZ
}

\begin{abstract}
Este trabalho propõe método de análise de resíduos de Clorpirifós em amostras de alface por cromatografia a líquido de alta eficiência (CLAE). A análise foi realizada em cromatógrafo Shimadzu, com detector de ultravioleta ajustado em $229 \mathrm{~nm}$, Coluna C-18, modelo Zorbax ODS (4,6 $\mathrm{mm} \times 25 \mathrm{~cm}, 5 \mu \mathrm{m})$, fluxo de $1 \mathrm{~mL} / \mathrm{min}$ e temperatura de $35^{\circ} \mathrm{C}$. Usou-se Metanol:Água (82:18) como fase móvel e volume injetado de $50 \mu \mathrm{L}$. Amostras de alface $(20 \mathrm{~g})$ foram trituradas e homogeneizadas na presença de $50 \mathrm{~mL}$ de Diclorometano (DCM). O material foi filtrado a vácuo e evaporado a temperatura de $50^{\circ} \mathrm{C}$. O resíduo foi retomado com fase móvel, agitado, desgaseificado, filtrado em membrana 0,22 $\mu \mathrm{m}$ e injetado no cromatógrafo (injetor automático). Os resultados do teste de repetitividade mostraram recuperação média de $101,91 \%$. O método proposto é simples e rápido para determinação de resíduos de Clorpirifós em amostras de alface.
\end{abstract}

PALAVRAS-CHAVE: INSETICIDA ORGANOFOSFORADO; CLORPIRIFÓS; CLAE; ALFACE.

Pesquisa desenvolvida no Laboratório de Agroquímica da Embrapa Milho e Sorgo, Sete Lagoas, MG, Brasil, como parte da Tese de doutoramento do primeiro autor.

** Doutoranda em Saneamento, Meio Ambiente e Recursos Hídricos, Escola de Engenharia, Universidade Federal de Minas Gerais (UFMG), Belo Horizonte; Bolsista CAPES (e-mail: marilena@uaimail.com.br).

*** Responsável Técnica pelo Laboratório de Resíduos de Agrotóxicos, Instituto Mineiro de Agropecuária (IMA), Belo Horizonte (e-mail: elianehooper@yahoo.com.br).

*** Engenheiro Civil e Sanitarista, Doutor, Professor Titular do Departamento de Engenharia Sanitária e Ambiental (DESA), UFMG, Belo Horizonte (e-mail: eduardo@desa.ufmg.br).

**** Doutor em Entomologia, Pesquisador da Embrapa Milho e Sorgo, Belo Horizonte (e-mail: ivancruz@cnpms.embrapa.br). 


\section{INTRODUÇÃO}

Clorpirifós [0,0-dietil-0-(3,5,6-tricloro-piridil)-fósforo-tionato], pertencente ao grupo dos inseticidas organofosforados, apresenta baixa solubilidade em água $(1,39 \mathrm{mg} / \mathrm{L})$ e alto coeficiente de sorção no solo $\left(\mathrm{K}_{\mathrm{oc}}=8498 \mathrm{~mL} / \mathrm{g}\right)(21)$. É altamente tóxico e muito perigoso para o meio ambiente (Classe II), sendo que o limite máximo permitido para resíduos de Clorpirifós (em grãos, vegetais e pastagens) varia de acordo com a cultura (3). Está registrado para o controle de diversas pragas (moscas, lagartas, ácaros, pulgões e outros), que atacam diversas culturas entre as quais milho, soja, trigo, sorgo, feijão, café, algodão, citros, maçã, banana, batata, cenoura, repolho, tomate, couve e fumo.

Clorpirifós encontra-se entre os principais inseticidas comercializados no Brasil (12), sendo indicado $(6,24,25)$ para aplicações via irrigação por aspersão (quimigação). Age sobre os insetos por contato, ingestão e fumigação (4). Como inibidor da colinesterase causa síndrome colinérgica, sendo, portanto, neurotóxico $(1,16,24)$. Sua toxicidade aguda $\left(\mathrm{DL}_{50}\right)$ oral em ratos é de $135-163 \mathrm{mg} / \mathrm{kg}$ e a dermal de $202 \mathrm{mg} / \mathrm{kg}$ (15).

Os inseticidas organofosforados (geralmente, muito tóxicos) constituem um dos principais responsáveis por intoxicações ocupacionais no campo. Quimicamente são ésteres do ácido fosfórico ou de ácidos derivados desse. Quando comparados com os clorados são considerados mais tóxicos, entretanto, não se acumulam em tecidos gordurosos. Como organofosforado, face à elevada lipossolubilidade que apresenta, Clorpirifós é absorvido pelo organismo humano, especialmente pela pele, além de membranas mucosas e pela via respiratória. O impacto na saúde do trabalhador rural está associado à exposição no momento de preparo da calda, aplicação na lavoura e durante a colheita. A absorção pelo trato gastrointestinal, normalmente, ocorre em intoxicações acidentais, suicídios e homicídios. Também pode ocorrer pelo consumo de frutas e verduras in natura contaminadas e destinadas ao consumo sem que o período de carência do agrotóxico seja observado (16,24).

Hortaliças e frutas comercializadas "de vez" e acondicionadas em geladeira podem sofrer alterações no nível de resíduos (como inativação, degradação ou mesmo acréscimo do referido nível), conforme observado em caquis (9) e mangas (20).

Usando a cromatografia, método físico-químico de separação dos componentes de uma mistura $(7,18)$, tem sido propostas várias metodologias para análise de resíduos de agrotóxicos em alimentos. Métodos desenvolvidos nas décadas de 60 e 70 por diferentes autores $(14,17,19$ e 23) constituem os mais usados. Tais métodos são trabalhosos, mas permitem a identificação simultânea de mais de uma centena de princípios ativos a partir da extração com solventes orgânicos e procedimentos de retirada de impurezas. A presença de interferentes nos alimentos vegetais, co-extraídos nas etapas de limpeza (e atribuídos a taninos, pigmentos, gorduras, dentre outros) em produtos como batata, tomate e hortaliças, comprometem a seletividade dos métodos e dificultam a obtenção de resultados em curto espaço de tempo, importante principalmente em análise de alimentos muito perecíveis (11).

Conforme GUIMARÃES (13), separações difíceis são, geralmente, conseguidas mais facilmente pela cromatografia a líquido de Alta Eficiência (CLAE) do que pela Cromatografia em Fase Gasosa (CG). Mesmo apresentando limitações como alto custo de instrumentação e operação, a CLAE tem sido cada vez mais usada em análises de resíduos de agrotóxicos pela versatilidade. Pode ser aplicada para compostos orgânicos e inorgânicos, em amostras líquidas ou sólidas, iônicas ou covalentes.

Análises de multirresíduos de agrotóxicos em alimentos, usando a Cromatografia em Fase Gasosa (CG), têm revelado a presença de Clorpirifós em culturas para as quais não está autorizado (incluindo alface). Níveis acima do permitido em culturas autorizadas também são verificados, muitas vezes como resultado de contaminação ambiental acidental ou pelo desrespeito às boas práticas agrícolas (2).

A alface, hortaliça consumida crua e muito popular no Brasil, constitui fonte de vitaminas e sais minerais. É comumente cultivada em hortas domésticas e comerciais, juntamente com outras culturas como couve, repolho e tomate, para as quais o Clorpirifós está autorizado. O desenvolvimento de 
novos métodos cromatográficos para determinação de resíduos de agrotóxicos usados em grande número de culturas assume importância, principalmente, pelo uso reduzido de solventes orgânicos resultando em menor exposição do analista e menor volume de descarte de solventes e pela seletividade do método, que favorece a obtenção de resultados rápidos e de forma menos onerosa.

Este trabalho teve como objetivo propor método rápido e simples de determinação de resíduos de Clorpirifós em amostras de alface, usando a Cromatografia a Líquido de Alta Eficiência (CLAE).

\section{MATERIAL E MÉTODOS}

\subsection{CONDIÇÕES CROMATOGRÁFICAS PARA ANÁLISE DE CLORPIRIFÓS}

Utilizou-se Cromatógrafo a Líquido de Alta Eficiência Shimadzu, modelo Class LC-10, com detector de ultravioleta, modelo SPD - 10A: $229 \mathrm{~nm}$. Foram estabelecidas as seguintes condições cromatográficas: Coluna C-18, modelo Zorbax ODS (4,6 mm x $25 \mathrm{~cm} \times 5 \mu \mathrm{m})$, SUPELCOSILTM LC-18, Pré-Coluna C-18, modelo Zorbax ODS (4,6 mm $\times 2 \mathrm{~cm})$, SUPELGUARDTM LC-18, Metanol-Água $\left(\mathrm{MeOH}: \mathrm{H}_{2} \mathrm{O}\right.$ ) na proporção 82:18 como fase móvel, temperatura de $35^{\circ} \mathrm{C}$, Fluxo de $1 \mathrm{~mL} / \mathrm{min}$ e volume de injeção de $50 \mu \mathrm{L}$.

Para a calibração do cromatógrafo foi utilizada a técnica do padrão externo. As curvas de calibração foram obtidas com duas séries de soluções padrões de Clorpirifós com concentrações entre 0,0625 e $1,00 \mu \mathrm{g} \cdot \mathrm{mL}^{-1}\left(R^{2}=0,99984\right)$ e entre 1,00 e $5,00 \mu \mathrm{g} \cdot \mathrm{mL}^{-1}\left(R^{2}=0,99976\right)$.

\subsection{PROCEDIMENTO PARA DETERMINAÇÃO DE CLORPIRIFÓS EM ALFACE}

Folhas de alface picadas e pesadas $(20 \mathrm{~g})$ foram colocadas em béqueres de $500 \mathrm{~mL}$, trituradas e homogeneizadas por aproximadamente 30 segundos, na presença de $50 \mathrm{~mL}$ do solvente Diclorometano (DCM). O material foi filtrado a vácuo, sendo usados kitazatos de $500 \mathrm{~mL}$, funis de Büchner, rolhas de silicone e filtros de papel Whatman número 1 . O filtrado foi submetido à evaporação do solvente, em temperatura de banho-maria máxima de $50^{\circ} \mathrm{C}$. O resíduo foi retomado com $5 \mathrm{~mL}$ da fase móvel $\left(\mathrm{MeOH}: \mathrm{H}_{2} \mathrm{O}\right)$, agitado, desgaseificado em aparelho de ultra-som, filtrado em filtro de membrana $0,22 \mu \mathrm{m}$ e injetado no CLAE com auxílio de injetor automático.

Durante o preparo das 100 (cem) amostras, cuidado especial foi tomado na limpeza do material não-descartável. O triturador foi limpo com papel toalha e acetona, aplicada com auxílio de pisseta após trituração de cada amostra. Toda a vidraria foi lavada com detergente, água corrente e água desmineralizada.

\section{RESULTADOS E DISCUSSÃO}

\subsection{PERFORMANCE ANALÍTICA}

Obteve-se limite de detecção (LD) de $0,02 \mu \mathrm{g} \cdot \mathrm{mL}^{-1}$, limite de quantificação (LQ) de $0,03 \mathrm{mg} \cdot \mathrm{Kg}^{-1}$ e percentagem de recuperação de 101,91\%. Apesar do tempo de retenção (saída do pico de Clorpirifós no cromatograma) de aproximadamente 12 minutos obtido nas condições cromatográficas estabelecidas, o tempo de corrida mínimo necessário para que os compostos da amostra (alface) sejam eluídos da coluna é de 60 minutos. Sendo assim, cem (100) amostras de alface foram analisadas em corridas programadas para 60 minutos, em grupos de 10, intercaladas por corrida do padrão 
Clorpirifós de $5 \mu \mathrm{g} \cdot \mathrm{mL}^{-1}$. Na Figura 1 podem ser observados diversos picos após o tempo de retenção do Clorpirifós (12 minutos), representando a eluição de diferentes compostos presentes na alface.

\section{FIGURA 1 - MULTICROMATOGRAMA APRESENTANDO CORRIDA TOTAL DE EXTRATOS (AMOSTRAS 99, 98, E 97) OBTIDOS DE AMOSTRAS DE ALFACE FORTIFICADAS + PADRÃO CLORPIRIFÓS $\left(5 \mu \mathrm{g} \cdot \mathrm{mL}^{-1}\right)$}

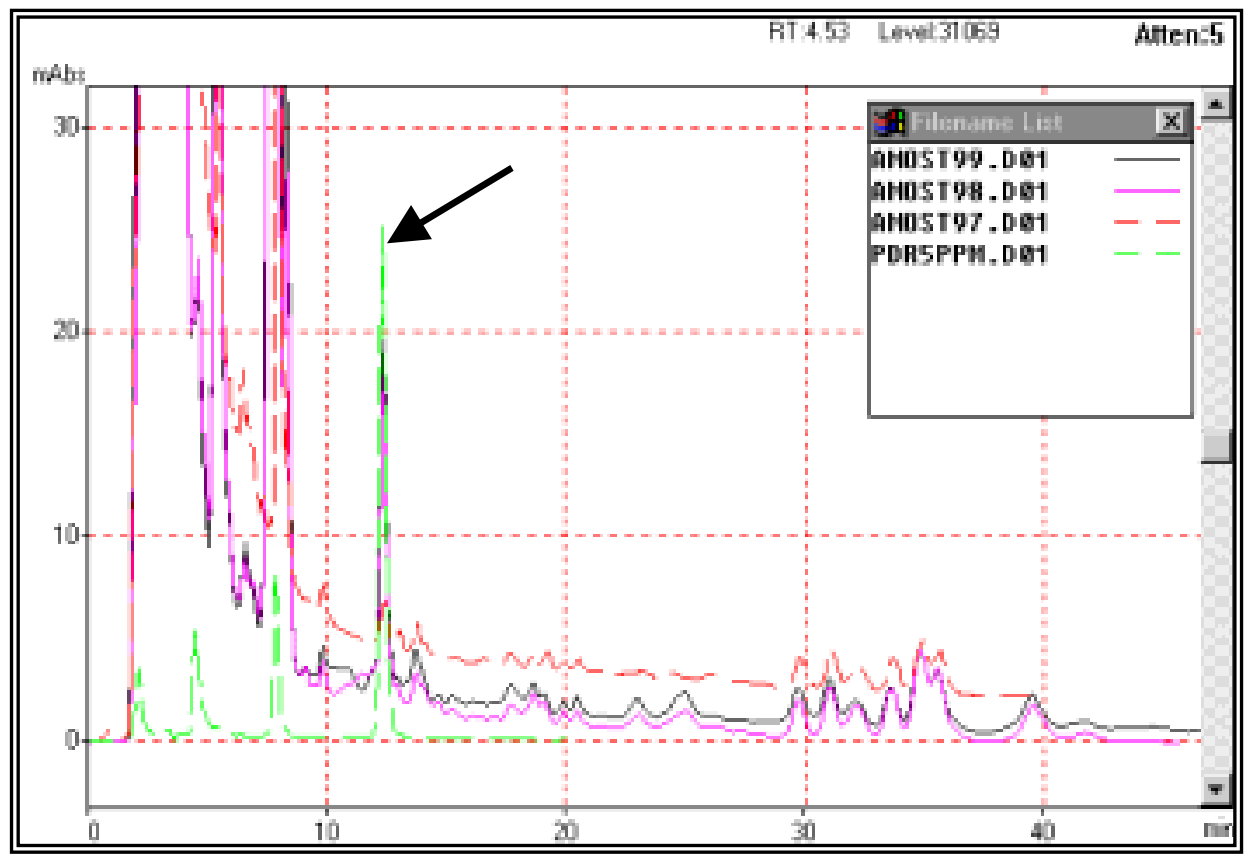

O resultado da determinação residual de Clorpirifós por CLAE em duas amostras de campo (plantas de alface expostas à aplicação de Clorpirifós) e uma amostra-testemunha (planta de alface não-exposta e livre da presença de Clorpirifós) é apresentado na Figura 2.

\subsection{TESTE DE REPETITIVIDADE}

Os resultados encontrados no teste de repetitividade das injeções de $50 \mu \mathrm{L}$ das soluções ( $L Q$, 2 LQ e 10 LQ) de Clorpirifós, diluídas em fase móvel, foram avaliados em função do tempo de retenção (Tabela 1), da área (Tabela 2) e da concentração (Tabela 3). O multicromatograma obtido está apresentado Na Figura 3.

\section{TABELA 1 - REPETITIVIDADE DAS INJEÇÕES DE CLORPIRIFÓS ( $\mu \mathrm{g} \cdot \mathrm{mL}^{-1}$ ), EM FUNÇÃO DO TEMPO DE RETENÇÃO (TR)}

\begin{tabular}{c|c|c|c|c|c|c|c}
\hline SOLU`^ & $g \cdot \mathrm{mL}^{-1}$ & TR1 & TR2 & TR3 & $x$ & $s$ & CV \\
\hline & & & & & & & \\
\hline LQ & 0,03 & 12,82 & 12,80 & 12,82 & 12,81 & 0,011 & 0,09 \\
\hline 2 LQ & 0,06 & 12,84 & 12,82 & 12,80 & 12,82 & 0,010 & 0,08 \\
\hline
\end{tabular}

CV = Coeficiente de variação. 
FIGURA 2 - MULTICROMATOGRAMA COMPARANDO PADRÃO CLORPIRIFÓS (5 $\left.\mu \mathrm{g} \cdot \mathrm{mL}^{-1}\right)$, EXTRATO 70B (AMOSTRA TESTEMUNHA) E EXTRATOS 79 E 80 (AMOSTRAS DE CAMPO)

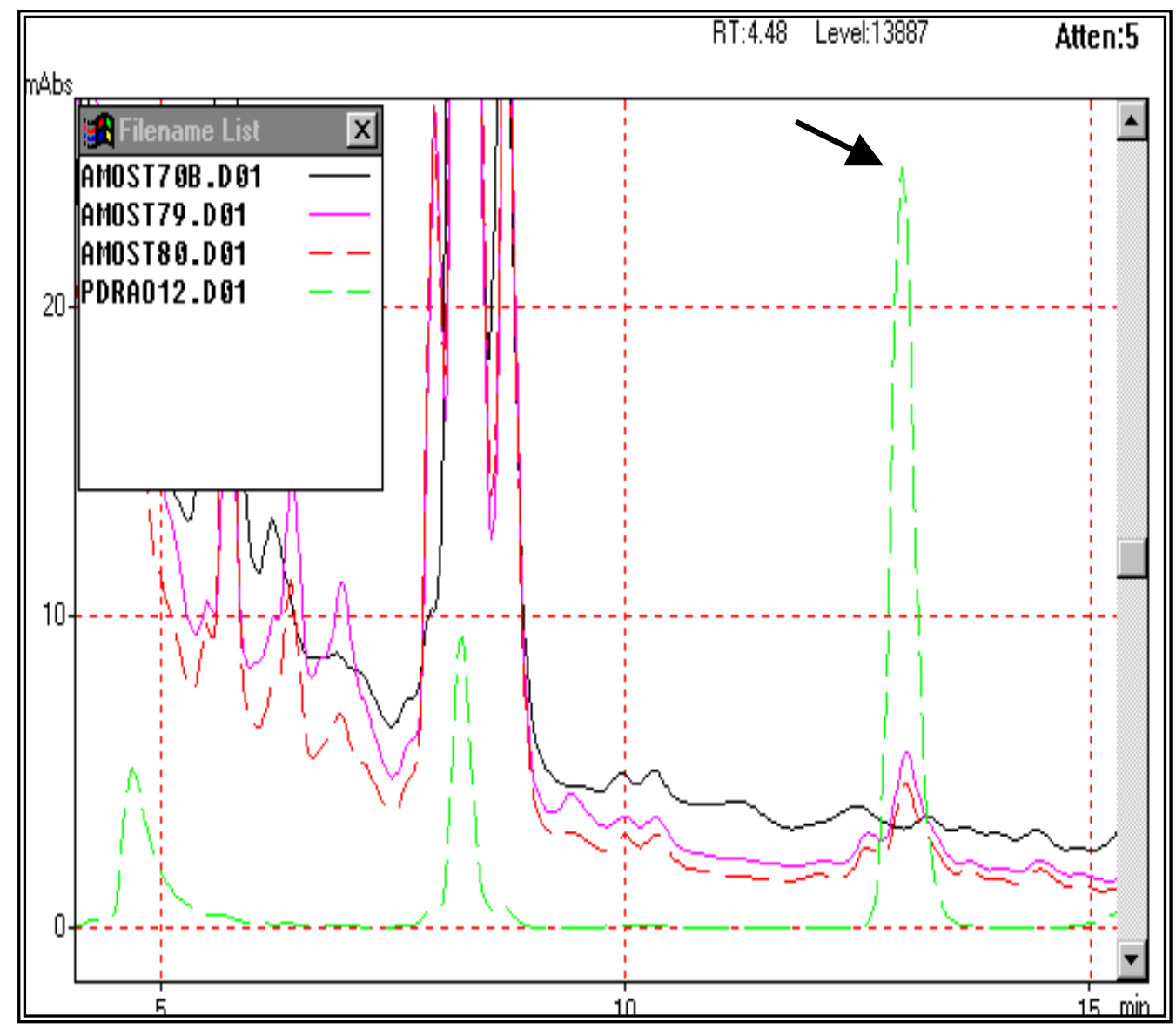

TABELA 2 - REPETITIVIDADE DAS INJEÇÕES DE CLORPIRIFÓS ( $\left.\mu \mathrm{g} \cdot \mathrm{mL}^{-1}\right)$ EM FUNÇÃO DA ÁREA (A)

\begin{tabular}{c|c|c|c|c|c|c|c}
\hline SOLU`^ & $\mathrm{g} \cdot \mathrm{mL}^{-1}$ & $\mathrm{~A} 1$ & $\mathrm{~A} 2$ & $\mathrm{~A} 3$ & $\mathrm{x}$ & $\mathrm{s}$ & $\mathrm{CV}$ \\
\hline & & & & & & & \\
\hline $\mathrm{LQ}$ & 0,03 & 2685 & 2533 & 2991 & 2736 & 233,26 & 8,53 \\
\hline $2 \mathrm{LQ}$ & 0,06 & 7878 & 7824 & 7801 & 7834 & 39,53 & 0,50 \\
\hline $10 \mathrm{LQ}$ & 0,30 & 34438 & 34516 & 34494 & 34483 & 40,22 & 0,12 \\
\hline
\end{tabular}

$\mathrm{CV}=$ Coeficiente de variação.

TABELA 3 - REPETITIVIDADE DAS INJEÇÕES DE CLORPIRIFÓS ( $\left.\mu \mathrm{g} \cdot \mathrm{mL}^{-1}\right)$, EM FUNÇÃO DA CONCENTRAÇÃO (C)

\begin{tabular}{l|c|c|c|c|c|c|c}
\hline SOLU`^ & $\mathrm{g} \cdot \mathrm{mL}^{-1}$ & $\mathrm{C} 1$ & $\mathrm{C} 2$ & $\mathrm{C} 3$ & $\mathrm{x}$ & $\mathrm{s}$ & $\mathrm{CV}$ \\
\hline & & & & & & & \\
\hline $\mathrm{LQ}$ & 0,03 & 0,0351 & 0,0336 & 0,0391 & 0,0359 & 0,0030 & 7,92 \\
\hline $2 \mathrm{LQ}$ & 0,06 & 0,0884 & 0,0878 & 0,0876 & 0,0879 & 0,0004 & 0,47 \\
\hline $10 \mathrm{LQ}$ & 0,30 & 0,3606 & 0,3614 & 0,3611 & 0,3610 & 0,0004 & 0,11 \\
\hline
\end{tabular}

$\mathrm{CV}=$ Coeficiente de variação. 
FIGURA 3 - MULTICROMATOGRAMA - 3 INJEÇÕES $(50 \mu L)$ DE SOLUÇÃO-PADRÃO CLORPIRIFÓS $\left(2 \mathrm{LQ}=0,06 \mu \mathrm{g} \cdot \mathrm{mL}^{-1}\right)$

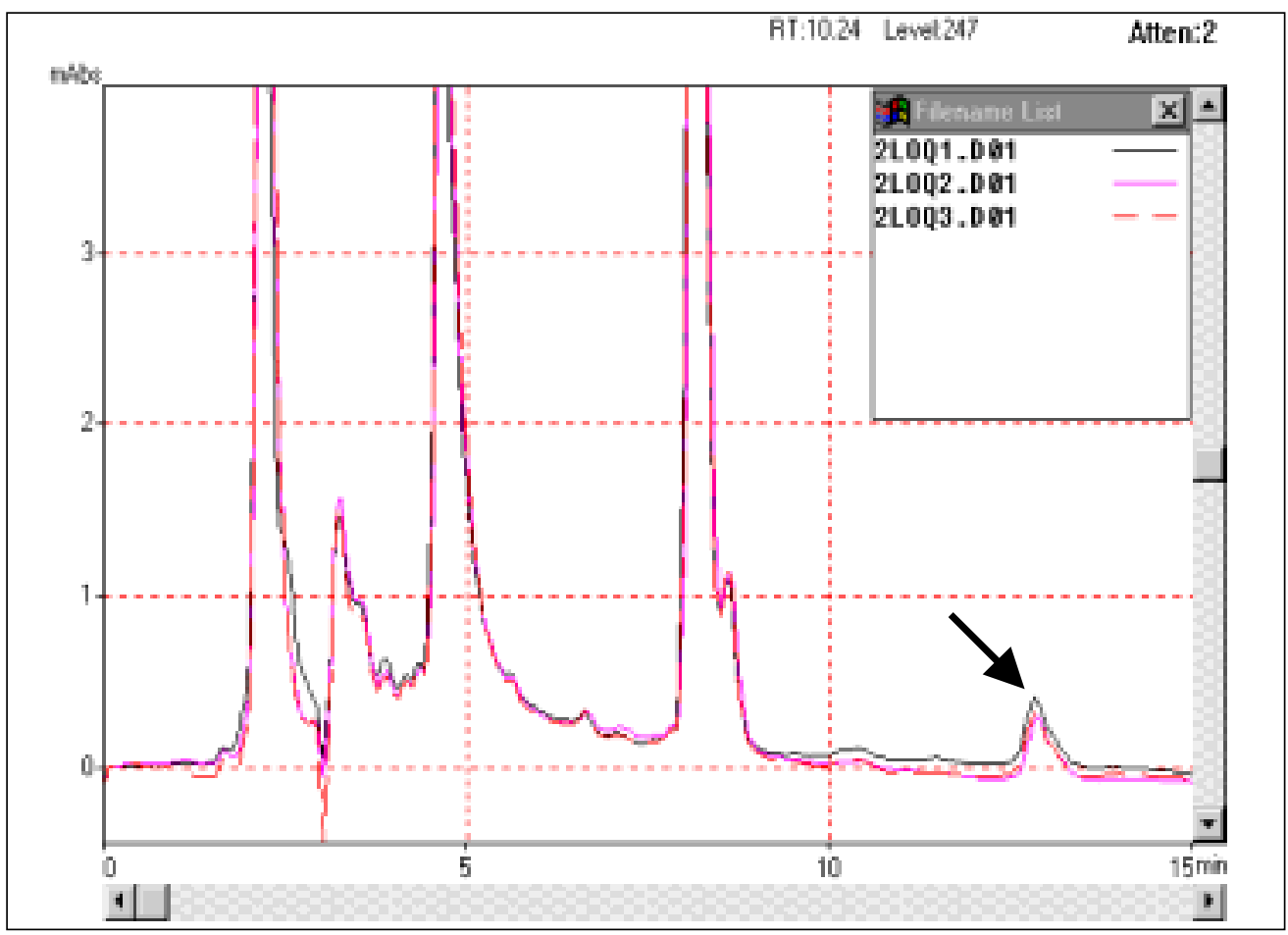

\subsection{TESTE DE RECUPERAÇÃO}

O método proposto para extração de Clorpirifós em amostras de alface foi avaliado pelo teste de recuperação, realizado em amostras-testemunha (em triplicata) fortificadas com solução-padrão de Clorpirifós $\left(5 \mu \mathrm{g} \cdot \mathrm{mL}^{-1}\right)$. Após evaporação do solvente (DCM), o resíduo foi retomado com $5 \mathrm{~mL}$ de fase móvel (MeOH: $\left.\mathrm{H}_{2} \mathrm{O}\right)(82: 18)$ e o resultado é apresentado na Tabela 4 e na Figura 4.

TABELA 4 - RESULTADO DO TESTE DE RECUPERAÇÃO DE CLORPIRIFÓS, EM AMOSTRAS DE ALFACE FORTIFICADAS COM SOLUÇÃO PADRÃO DE CLORPIRIFÓS $\left(5 \mu \mathrm{g} \cdot \mathrm{mL}^{-1}\right)$

\begin{tabular}{|c|c|c|c|c|}
\hline Amostra & Tempo de reten $\stackrel{a}{a} 0$ & concentra ${ }^{a} 0$ & concentra ${ }^{a} 0$ & recupera ${ }^{a} 0$ \\
\hline N" & de Clorpirif $\mathrm{s}$ & adicionada & determinada & $\%$ \\
\hline & (minutos) & $\left(\mathrm{g} \cdot \mathrm{mL}^{-1}\right)$ & $\left(\mathrm{g} \cdot \mathrm{mL}^{-1}\right)$ & \\
\hline 97 & 12,33 & 5,00 & 4,9830 & 99,66 \\
\hline 98 & 12,27 & 5,00 & 5,1638 & 103,28 \\
\hline 99 & 12,26 & 5,00 & 5,1395 & 102,79 \\
\hline
\end{tabular}

$\mathrm{x}=101,91 ; \mathrm{s}=1,96 ; \quad \mathrm{CV}=1,92 ; \quad \mathrm{CV}=$ Coeficiente de variação.

A recuperação média (101,91\%) mostrou-se semelhante às encontradas por RACKE et.al. (1996), que analisaram Clorpirifós por CLAE em 37 diferentes solos e obtiveram 101,68\% de recuperação. BOGUS et al. (1990) analisaram, por CLAE, 7 agrotóxicos em água e obtiveram recuperação de 93,7\% para Clorpirifós. LAABS et. al. (1999), propuseram método para análise de multirresíduos de agrotóxicos por CG em solos tropicais. Constataram recuperação de $98 \%$ para Clorpirifós. 
FIGURA 4- MULTICROMATOGRAMA DAS AMOSTRAS AVALIADAS EM TESTE DE RECUPERAÇÃO + PADRÃO CLORPIRIFÓS

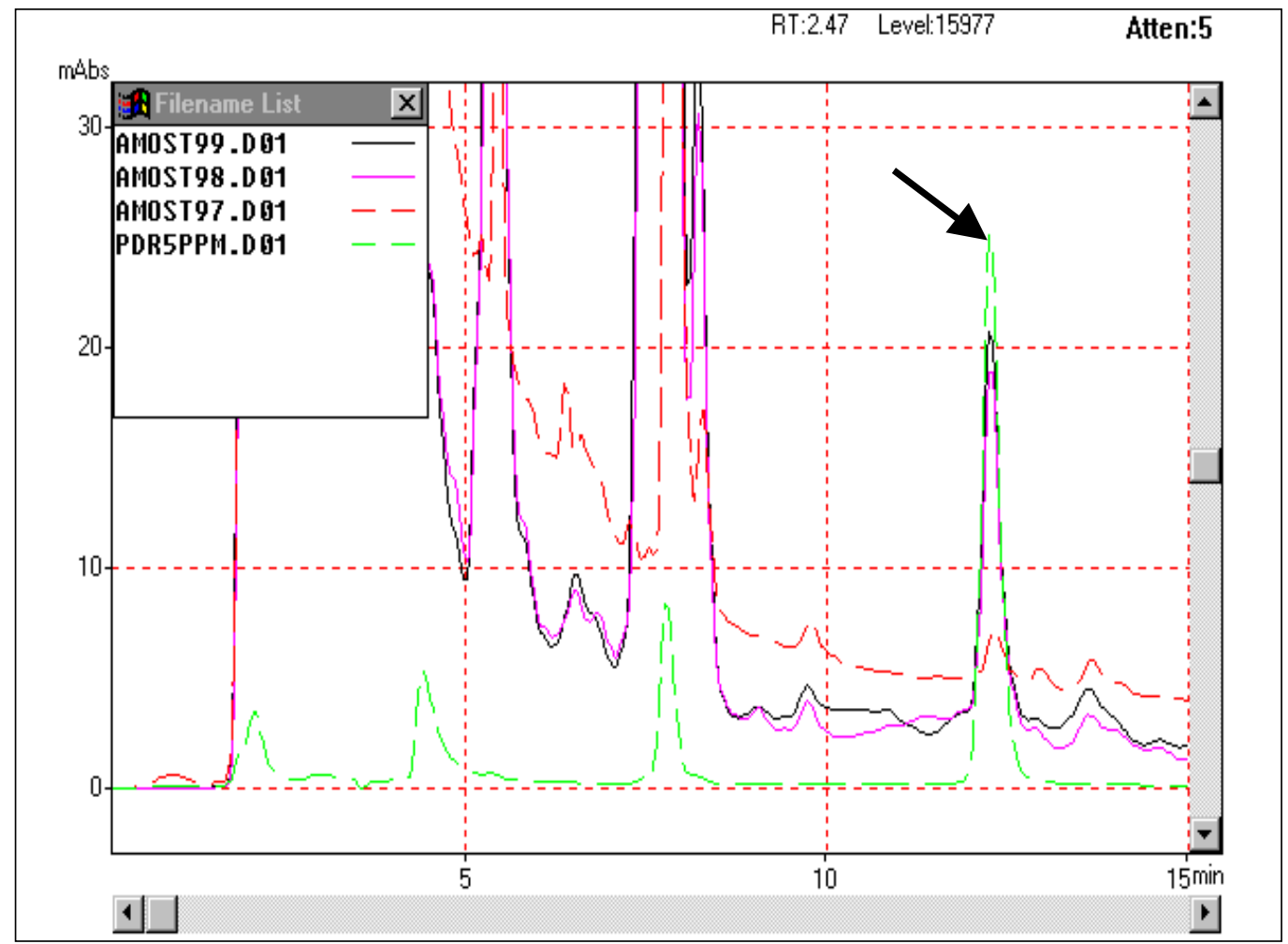

\title{
4 CONCLUSÃO
}

Considerando a performance analítica, o método proposto apresenta-se como ferramenta alternativa para determinação de resíduos de Clorpirifós em amostras de alface. A técnica escolhida (CLAE) possibilitou a determinação de Clorpirifós de forma rápida, simples e com baixo custo.

\begin{abstract}
METHOD FOR THE DETERMINATION OF CHLORPIRYFOS RESIDUES IN LETTUCE BY USING HPLC (High Performance Liquid Cromatograph)

This paper suggests a method for the residual analysis of chlorpiryfos in lettuce samples by using HPLC (High Performance Liquid Cromatograph). The analysis has been carried out in a Shimadzu cromatograph, with ultraviolet detector adjusted to $229 \mathrm{~nm}$, column C-18, model Zorbax ODS $(4.6 \mathrm{~mm} \times 25 \mathrm{~cm}, 5 \mu \mathrm{m})$, flux $1 \mathrm{~mL} / \mathrm{min}$, temperature of $35^{\circ} \mathrm{C}$. The mobile phase used was methanol:water (82:18) and the injected volume of $50 \mu \mathrm{L}$. Lettuce samples have been triturated and homogenized in the presence of $50 \mathrm{~mL}$ of the solvent Dichlormethan (DCM). The vacuum filtered material was evaporated at the temperature of $50^{\circ} \mathrm{C}$. The residue has been retaken in a mobile phase, stirred, degasified, filtered in a $0.22 \mu \mathrm{m}$ membrane and automatically injected in the HPLC. Good results were obtained in a repetitivity test, with an average recovery of $101.91 \%$. The proposed test presents simplicity and quickness in the residual determination of Chlorpiryfos in lettuce samples.

KEY-WORDS: ORGANOPHOSPHORUS INSECTICIDES; CHLORPYRIFOS; HPLC; LETTUCE.
\end{abstract}

\section{REFERÊNCIAS}

1 AGROTÓXICOS: informações para uso médico, sintomas de alerta e tratamento das intoxicações. 2.ed. Rio de Janeiro: Souza Cruz, 1998. 167 p.

2 AMARAL, E.H.; PARMA, C. Controle de resíduo de agrotóxico em produtos agrícolas. In: SEMINÁRIO NACIONAL SOBRE AGROTÓXICOS, Belo Horizonte, MG, out. 2002. (Palestra não-publicada). 
BAPTISTA, G. C. de. Toxicologia alimentar e ambiental de pesticidas. In: BAPTISTA, G. C.; BAHIA FILHO, O.; TREVIZAN, L. R. P. Análise de resíduos de pesticidas em matrizes agronômicas por métodos cromatográficos. Piracicaba: FEALQ/USP, 2002. p.1-72.

4 BOGUS, E.R.; WATSCHKE, T.L.; MUMMA, R.O. Utilization of solid-phase extraction and reversed-phase and ion-pair chromatography in the analysis of seven agrochemicals in water. Journal of Agricultural and Food Chemistry, Washington, v. 38, p.142-144, 1990.

5 BRASIL. Ministério da Saúde. Agência Nacional de Vigilância Sanitária. Toxicologia. Disponível em: $<$ http//:www.anvisa/toxicologia/monografia/clorpirifos>. Acesso em abr. 2003.

CHALFANT, R.B.; YOUNG, J.R. Management of insect pests of broccoli, cowpeas, spinach, tomatoes and peanuts with chemigation by insecticides in oil, and reduction of watermelon virus 2 by chemigated oil. Journal of Economic Entomology, College Park, v. 77, p. 1323-1326, 1984.

7 COLLINS, C. H.; BRAGA, G. L.; BONATO, P. S. Introdução a métodos cromatográficos. Campinas: UNICAMP, 1993. 279 p. (Série Manuais).

8 CRUZ, I. A lagarta do cartucho na cultura do milho. Sete Lagoas: EMBRAPA -CNPMS, 1995.45 p. (EMBRAPACNPMS, Circular Técnica, 21).

9 FAO. Food and Agriculture Organization. Pesticide residues in food. Evaluations, v. 67, p.355-373, 1984.

FERRAZ, V. Cromatografia líquida de alta eficiência. Belo Horizonte: Departamento de Química/UFMG, out. 2001. $33 \mathrm{p}$.

11 FODOR-CSORBA, K. Chromatographic methods for the determination of pesticides in foods. Journal of Chromatography A., Amsterdam, n.624, p. 353-367, 1992.

12 GUILHERME, L. R. G.; SILVA,M. L. N.; LIMA, J.M. de; RIGITANO, R.L.O. Contaminação de microbacia hidrográfica pelo uso de pesticidas. Informe Agropecuário, Belo Horizonte, v.21, n. 207, p.40-50, nov./dez. 2000.

13 GUIMARÃES, L. F. L. Cromatografia líquida de alta eficiência. In: COLLINS, C. H.; BRAGA, G. L.; BONATO, P. S. Introdução a métodos cromatográficos. Campinas: UNICAMP, 1993. p.183-238.

14 KRAUSE, R.T. Further characterization and refinement of an HPLC post-column fluorometric labeling techinique for the determination of carbamate insecticides. Journal of Chromatographic Science, Niles, v.16, n.7, p.281-288, 1978.

15 LAABS, V.; AMELUNG, W.; ZECH, W. Multi-residue analysis of corn and soybean pesticides in brazilian oxisols using gas chromatography and mass selective detection. Journal of Environmental Quality, Madison, v.28, p.1778-1786, 1999 .

LARINI, L. Toxicologia de praguicidas. São Paulo: Manole, 1999. 230 p.

LUKE, M.A.; FROBERG, J.E.; MASUMOTO, H.T. Extraction and clean up of organochlorine, organophosphate, organonitrogen and hydrocarbon pesticides in produce for determination by gas-liquid chromatography. Journal of the Association of Official Analytical Chemists, Washington, v. 58, n.5, p. 1020-1026, 1975.

MEYER, V. R. Practical high-performance liquid chromatography. $2^{\text {nd }}$ ed. London: British Library, 1993.376 p.

MILLS, P.A.; ONLEY, J.H.; GAITHER, R.A. Rapid method for chlorinated pesticide residues in nonfatty foods. Journal of the Association of Official Analytical Chemists, Washington, v. 46, p. 186-191, 1963.

PAPADOPOULOU-MOURKIDOU, E. Posthaharvest-applieed agrochemicals and their residues in fresh fruits and vegetables. Journal of the Association of Analytical Chemists, Washington, v. 74, n.5, p. 745-765, 1991.

21 RACKE, K.D. Environmental fate of chlorpyrifos. Reviews of Environmental Contamination and Toxicology, New York, v.131, p.1-154, 1993

RACKE, K.D.; STEELE,K.P.; YODER, R.N.; DICK, W.A.; AVIDON, E. Factors affeting the hidrolytic degradation of chlorpyrifos in soil. Journal of Agricultural Food Chemistry, Washington, v.44, p. 1582-1592, 1996.

23 STORHERR, R.W.; WATTS, R.R. Identification and analysis of five organophosphate pesticides: recoveries from crops fortified at different levels. Journal of the Association of Official Analytical Chemists, Washington, v.47, p. 1087-1093, 1964.

TRAPÉ, A. Z. Doenças relacionadas a agrotóxicos: um problema de saúde pública. Campinas, 1995.171 f. Tese (Doutorado), Universidade de Campinas.

VIANA,P.A.; COSTA, E.F. Controle da lagarta-do-cartucho (Spodoptera frugiperda J.E.Smith) na cultura do milho com inseticidas aplicados via irrigação por aspersão. Anais da Sociedade Brasileira de Entomologia, Jaboticabal, v.27, n.3, p.451-458, 1998 . 